\title{
Comparação in vitro de dois protocolos de concentrado plaquetário equino
}

Betsabéia Heloísa Gentilha Milani", Ivanio Teixeira de Borba Junior,Jaqueline Brandão de Souza, Vitor Hugo Santos, João Pedro Hübbe Pfeifer, Gustavo dos Santos Rosa, Andre Massahiro Teramoto Krieck, Caio Nunes de Barros, Ana Liz Garcia Alves

Faculdade de Medicina Veterinária e Zootecnia, Universidade Estadual Paulista (UNESP), Botucatu, SP, Brasil

*Autor correspondente

e-mail: betinhamilani@gmail.com

\section{Resumo}

O concentrado de plaquetas (CP) é obtido a partir do processamento do plasma rico em plaquetas (PRP), considerado um subproduto derivado do plasma. A procura por produtos ricos em fatores de crescimento na medicina regenerativa está em grande expansão. Existem diversos protocolos para obtenção do PRP e seus subsequentes derivados para a medicina esportiva equina. A indicação para o uso intra-articular é grande, mas devido à reação inflamatória exacerbada, a escolha do protocolo utilizado deve ser realizada com parcimônia. Sendo assim, este resumo tem como objetivo comparar os resultados de dois protocolos utilizados em medicina equina. Para esta comparação foram utilizadas 12 amostras de sangue total de seis equinos hígidos em duplicata, sendo seis amostras por protocolo. Protocolo 1 (P1): coleta do sangue total por venopunção em tubo de citrato de sódio 3,2\%; descanso por 30 minutos em local protegido de luz; primeira centrifugação a 300G por 5 minutos; segundo descanso por 30 minutos ao abrigo da luz; subsequentemente, é separado o plasma do sangue total sem a camada de leucócitos (buffy-coat); segunda centrifugação por 700G a 15 minutos; e, após o terceiro descanso de 40 minutos, é descartado 75\% do plasma pobre em plaquetas (PPP), o restante é homogeneizado e obtêm o CP. Protocolo 2 (P2): coletado o sangue total por venopunção em tubo de citrato de sódio 3,2\%; centrifugação a 450G por 10 minutos; foi separado o plasma e realizada a segunda centrifugação a $2800 \mathrm{G}$ por 15 minutos. Após formar o botão plaquetário, foi descartado 75\% do PPP e homogeneizado. Os resultados foram: Animal 1) Valor basal das plaquetas: 177.000/ $\mu \mathrm{L}, \mathrm{P} 1$ Plaquetas: 459.000/ $\mu \mathrm{L} /$ Leucócitos: 8.500/ $\mu \mathrm{L}$, P2 Plaquetas: 457.025/ $\mu \mathrm{L} /$ Leucócitos: 600/ $\mu \mathrm{L} ;$ Animal 2)

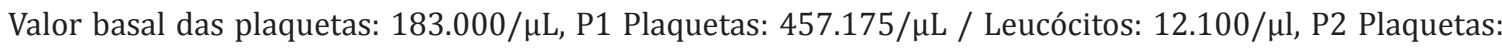

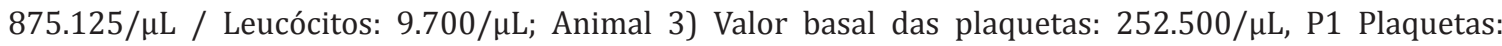

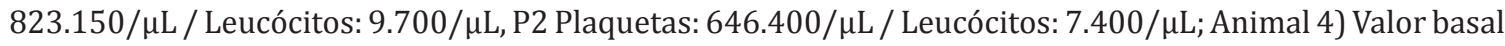

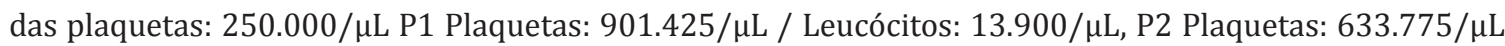


/ Leucócitos: 12.000/ $\mu \mathrm{L}$; Animal 5) Valor basal das plaquetas: 103.525/ $\mu \mathrm{L}, \mathrm{P} 1$ Plaquetas: 373.700/ $\mu \mathrm{L} /$

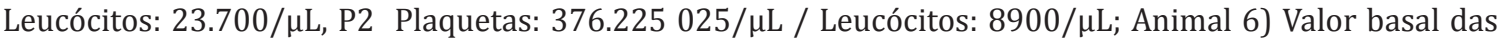
plaquetas: 154.025/ $\mu \mathrm{L}, \mathrm{P} 1$ Plaquetas: 664.075/ $\mu \mathrm{L} /$ leucócitos: 25.900/ $\mu \mathrm{L}, \mathrm{P} 2$ Plaquetas: 585.800/ $\mu \mathrm{L} /$ Leucócitos: 100/ $\mu \mathrm{L}$.0 protocolo 1 teve como resultado a média de 15.633 leucócitos/ $\mu \mathrm{L}$, correspondendo a 2,89\% da celularidade total do concentrado plaquetário. Já o protocolo 2 obteve 6.600 leucócitos/ $\mu \mathrm{L}$, que correspondem a 1,14\% da celularidade final. Após contagem manual de células (leucócitos e plaquetas) em câmara de Neubauer e análise das médias e dos percentuais relativos, os resultados mostraram que os dois protocolos foram eficientes em concentrar plaquetas. No entanto, o protocolo 1 obteve maior concentração leucocitária. Os resultados demonstraram a eficiência de ambos os protocolos em concentrar plaquetas. No entanto, o protocolo 2 apresentou percentual leucocitário menor, tornando-se mais adequado ao uso e aplicação intra-articular em equinos, visto que a alta porcentagem leucocitária é desfavorável à regeneração do ambiente articular.

Palavras-chave: Equinos. Medicina regenerativa. Plaquetas. 